American J. of Engineering and Applied Sciences 3 (1): 171-179, 2010

ISSN 1941-7020

(C) 2010 Science Publications

\title{
Low-doping Effects of Nanostructure ZnO: Sn tin films annealed at different temperature in Nitrogen ambient to be applied as an Anti-reflecting coating (ARC)
}

\author{
${ }^{1}$ H. Abdullah, ${ }^{1}$ M.N. Norazia, ${ }^{2}$ S.Shaari, ${ }^{3}$ M.Z. Nuawi and ${ }^{4}$ N.S. Mohamed Dan \\ ${ }^{1}$ Department of Electric, Electronic and System Engineering, \\ Faculty of Engineering and Built Environment, \\ University Kebangsaan Malaysia, 43600 Bangi, Selangor, Malaysia \\ ${ }^{2}$ Institute of Micro-Engineering and Nanoelectronics, \\ University Kebangsaan Malaysia, 43600 Bangi, Selangor, Malaysia \\ ${ }^{3}$ Department of Mechanical and Materials, Faculty of Engineering, \\ University Kebangsaan Malaysia, 43600 Bangi, Selangor, Malaysia \\ ${ }^{4}$ Institute of Mathematical Research, University Putra Malaysia, \\ 43400 UPM Serdang, Selangor, Malaysia
}

\begin{abstract}
Problem statement: The focus of this research is to discover the significant influences of substituting low concentration $\mathrm{Sn}$ at $\mathrm{Zn}$-site as an Anti-Reflecting Coating (ARC) for $\mathrm{Zn}_{1-\mathrm{x}} \mathrm{Sn}_{\mathrm{x}} \mathrm{O}$ compound. The effects of tin dopants on the structural and morphology properties of $\mathrm{ZnO}$ thin films prepared using the sol-gel method were investigated. Approach: The effects of annealing temperature on the deposited films were also investigated at three different temperatures of 400,500 and $600^{\circ} \mathrm{C}$. The composition of the $\mathrm{Zn}_{1-\mathrm{x}} \mathrm{Sn}_{\mathrm{x}} \mathrm{O}$ sample are $\mathrm{x}=0.00,0.05,0.10$ and 0.15 . As a starting material, zinc acetate dehydrate was used; 2-methoxyethanol and mono ethanolamine were used as solvent and stabilizer, respectively. The dopant source was tin chloride. Results: Microstructural and surface morphology of samples were characterized by using Scanning Electron Microscopy (SEM). The crystallinity and defects are studied using X-Ray Diffraction (XRD). Molecular bonding is carried out using Raman spectroscopy and optical study of band gap is investigated using UV-VIS measurement. Conclusion: The value of band gap obtained increased slightly as the concentration of $\mathrm{Sn}$ increased. The increment of the band gap is acceptable as a requirement for good anti-reflecting coating element. Therefore these films can be applied on silicon solar cell.
\end{abstract}

Key words: Zinc oxide, sol-gel method, thin films, doped Sn, annealing

\section{INTRODUCTION}

Metal oxide semiconductor films have been widely studied and have received considerable attention in recent years due to their optical and electrical properties. Some of them are good prospects as transparent conductive oxide films. Among them, $\mathrm{ZnO}$ is one of the metal oxide semiconductors that are suitable for use in optoelectric devices. It is an alternative material to tin oxide and indium tin oxide, which is most used to date (Lee and Park, 2003). ZnO is an n-type wide band gap semiconductor $\left(\mathrm{E}_{\mathrm{g}}=3.2\right.$ $\mathrm{eV}$ ). Its large exciton binding energy of $60 \mathrm{MeV}$ at room temperature and electrical conductivity are due to intrinsic and extrinsic defects. The conductivity of pure
$\mathrm{ZnO}$ is produced by the former defects such as zinc excess at the interstitial position and the lack of oxidation. Since pure $\mathrm{ZnO}$ thin films are sensitive to oxidation, absorption of $\mathrm{O}_{2}$ in the films is inclined to decrease its electrical conductivity. In cases where $\mathrm{ZnO}$ is doped with different dopants, the electrical properties are enhanced by extrinsic defects and these trials have been attempted. Additionally, electrical properties of $\mathrm{ZnO}$ can be modified by thermal treatment in a reducing atmosphere. The optical properties of $\mathrm{ZnO}$ were mainly affected by a surface morphology and the change of the optical energy band gap followed by heavy doping. The material's morphology was also modified by thermal treatment in a reducing atmosphere and by an appropriate doping process (Lee

Faculty of Engineering and Built Environment, University Kebangsaan Malaysia, 43600 Bangi, Selangor, Malaysia 
and Park, 2003). $\mathrm{ZnO}$ is one of the metal-oxide semiconductors that has been utilized to be very useful functional materials for devices such as UV-light emitters, varistors, transparent high power electronics, surface acoustic wave devices, piezoelectric transducers, gas sensing, solar cells and structural materials such as window material for display (Shan et al., 2003). As grown, ZnO usually exhibits ntype conductivity with a wide band gap. The n-type conductivity might be caused by intrinsic defects, interstitial zinc and oxygen vacancies. Its electrical conductivity can be increased by doping it with group III elements such as aluminum, boron, gallium and indium, or group VII elements such as fluorine (Nunes et al., 2002). $\mathrm{ZnO}$ thin films can be prepared by a variety of thin film deposition techniques, such as pulsed-laser deposition (Shim et al., 2002), RF magnetron sputtering (Nunes et al., 2002), chemical vapor (Kashiwaba et al., 2000), spray pyrolysis (Paraguay et al., 1999) and the sol-gel process (Lee and Park, 2003). While physical deposition such as pulsed-laser deposition and RF magnetron sputtering produces films with good electrical and optical properties at lower deposition temperature, it has the disadvantage of a relative low deposition rate and expensive equipment. However, the sol-gel technique offers the greatest possibility of preparing small as well as large area coating of $\mathrm{ZnO}$ thin films at low cost for technological applications and is widely compatible with microelectronic technology, circuit and anti reflecting coating for solar cells (Lee and Park, 2003).

As one of the promising metal oxide materials in the semiconductor field (due to its potential properties), $\mathrm{ZnO}$ has received considerable attention in the recent years (Shan et al., 2004; Look, 2001). In this study, the effects of dopant and their doping concentration on the microstructure and morphology properties of doped $\mathrm{ZnO}$ thin films were investigated to produce films that can be applied on thin solar cells with improved efficiency.

\section{MATERIALS AND METHODS}

$\mathrm{ZnO}$ thin films are prepared by the sol-gel method. As a starting material, zinc acetate dehydrate $\left(\mathrm{Zn}\left(\mathrm{CH}_{3} \mathrm{COO}\right)_{2} \cdot 2 \mathrm{H}_{2} \mathrm{O}\right)$ is used. Two-methoxyethanol and Monoethanolamine (MEA) are used as a solvent and a stabilizer, respectively. The dopant source of tin is tin chloride $\left(\mathrm{SnCl}_{4}\right)$. Zinc acetate dehydrate and dopant is first dissolved in a mixture of 2methoxyethanol and MEA solution at the room temperature. The molar ratio of MEA to zinc acetate $\left(\mathrm{Zn}\left(\mathrm{CH}_{3} \mathrm{COO}\right)_{2}\right)$ is maintained at 1.0 and the concentration of zinc acetate was $0.5 \mathrm{M}$. The solution is stirred at $60^{\circ} \mathrm{C}$ for $2 \mathrm{~h}$ to yield a clear and homogeneous solution, which served as the coating solution after it cooled to the room temperature. The coating is usually made 2 days after the solution is prepared.

The solution is dropped onto quartz substrates, which are rotated at $1000 \mathrm{rpm}$ for $30 \mathrm{sec}$. After depositing by spin coating, the films are dried at $150^{\circ} \mathrm{C}$ for $10 \mathrm{~min}$ over a hot plate to evaporate the solvent and remove organic residuals. The procedures from coating to drying are repeated three times until the thickness of the sintered films is approximately $200 \mathrm{~nm}$. The films are then inserted into a furnace and annealed with $5 \%$ nitrogen at different temperatures which are 400, 500 and $600^{\circ} \mathrm{C}$ for $1 \mathrm{~h}$. The crystallization of each $\mathrm{ZnO}$ film is measured using an X-ray diffractometer with $\mathrm{CuK}_{\mathrm{a}}$ radiation. The surface morphology and chemical composition of the films are observed with a Scanning Electron Microscope (SEM) and Energy Dispersive Xray (EDX). The changes in chemical bonding are measured by a Raman spectroscopy and the optical properties by UV-Vis measurement.

\section{RESULTS}

Figure1 shows the X-ray diffraction patterns of $\mathrm{ZnO}$ thin films undoped and doped with tin at 5\%. The temperature differential for each sample changed from $400-600^{\circ} \mathrm{C}$. X-ray diffraction spectra of all the films are taken at room temperature. The peaks, with the Miller indices given belong to the $\mathrm{ZnO}$. The presence of sharp structural peaks in these X-ray diffraction patterns confirmed the polycrystalline nature of the films. All films, undoped and doped, regardless of dopants and their temperature differential, are thin films and have (0 02 ) as the preferred orientation. The $5 \%$ tin doped $\mathrm{ZnO}$ at $500^{\circ} \mathrm{C}, 5 \%$ tin doped $\mathrm{ZnO}$ at $500^{\circ} \mathrm{C}$ and $15 \%$ tin doped $\mathrm{ZnO}$ at $600^{\circ} \mathrm{C}$ thin film had the highest $\left(\begin{array}{lll}0 & 0 & 2\end{array}\right)$ diffraction peak intensity than that of the others. Moreover, the peak intensities of those films increased with increased temperature of those films. This indicates that an increase in temperature deteriorates the crystallization of films, which may be due to the formation of stresses by the difference in ion size between zinc and the dopant and the segregation of dopants in grain boundaries (for high doping concentrations). This $\left(\begin{array}{lll}0 & 0 & 2\end{array}\right)$ preferred orientation is due to the minimal surface energy which the hexagonal structure, c-plane to the $\mathrm{ZnO}$ crystallites, corresponds to the densest packed plane as we can see in morphology structure. Overall, another orientation presented at $\left(\begin{array}{ll}1 & 0\end{array}\right.$ 1) and (lll 100$)$, also seen in Fig. 1.

SEM images of undoped and doped $\mathrm{ZnO}$ thin films on quartz substrates are displayed in Fig. 2. These SEM images show that the surface morphology of the films is strongly dependent on the annealing and concentration of the dopant. A particular structure is observed in SEM images for all films. For tin doped films, particles with 
Am. J. Engg. \& Applied Sci., 3 (1): 171-179, 2010
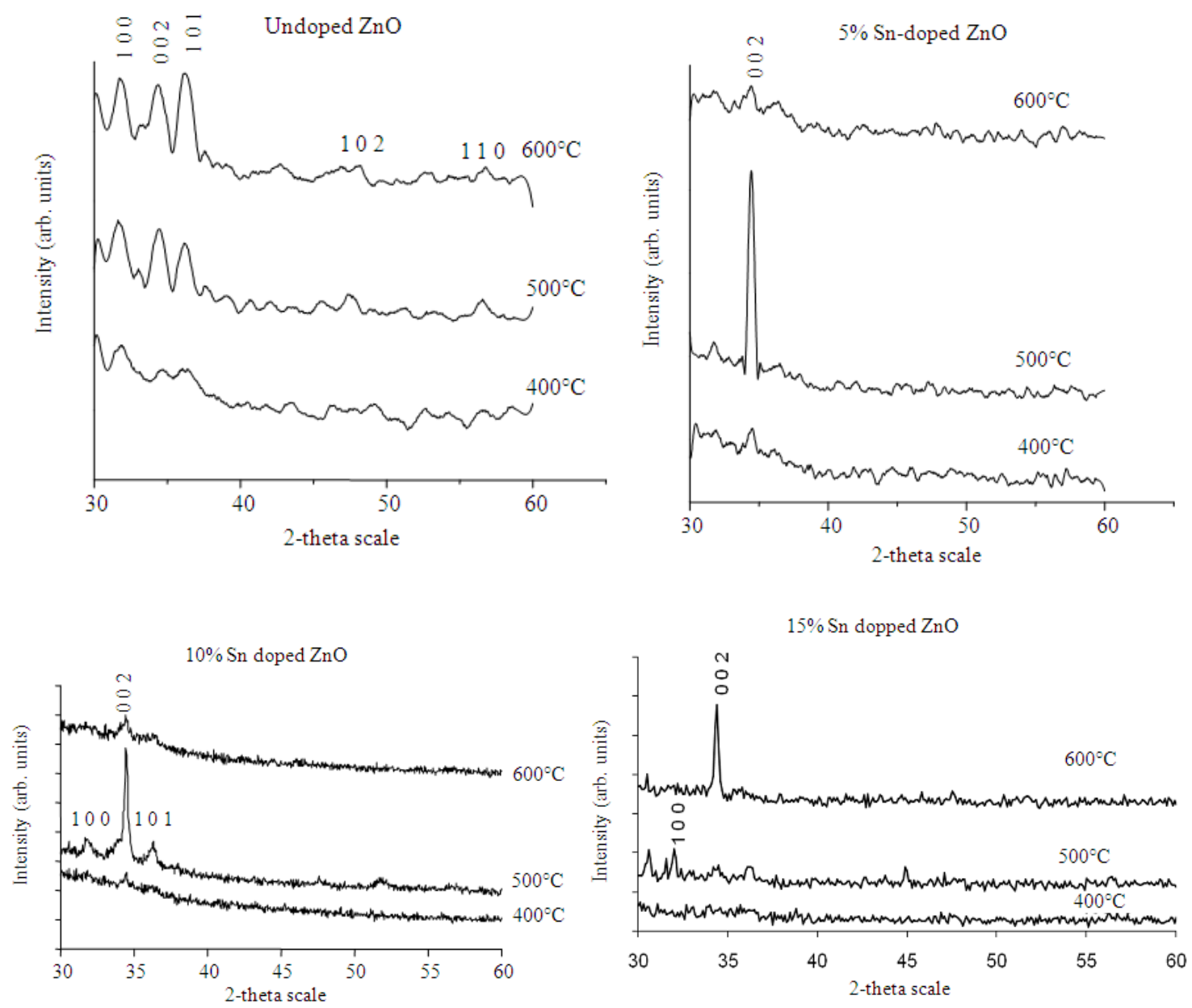

Fig. 1: X-ray diffraction patterns of $\mathrm{ZnO}$ doped with tin at 5, 10 and $15 \%$ thin films as a function of temperature differential

different shapes and sizes were mixed. The film with annealed $400^{\circ} \mathrm{C}$ had particles size of approximately $48 \mathrm{~nm}$. When the annealing temperature was at $500^{\circ} \mathrm{C}$, the particle size decreased and the microstucture of the film became denser. The $600^{\circ} \mathrm{C}$ annealed film consisted of small particles forming a matrix where the large ones lying on the matrix. The particle size forming a matrix reduces with increasing annealing temperature.

Additionally, a microstructure with a larger difference in size between the large and small particles is observed in films annealed at $600^{\circ} \mathrm{C}$. In cases where films doped with tin with smaller ionic radius than zinc, particles forming matrix became smaller with increased annealing temperature. This is because the grain growth is disturbed by compression stresses due to the difference in ionic radii between zinc and tin $\left(\mathrm{r}_{\mathrm{Sn}}{ }^{4+}=0.069 \mathrm{~nm}\right)$. The change in particle size with an increase in annealing temperature is observed to occur more in the tin doped films than in the undoped films. This is due to a higher difference in ionic radius between zinc and tin, this behavior also has been observed by Lee and Park 2003 annealed at $500^{\circ} \mathrm{C}$.

$\mathrm{ZnO}$ crystallizes in the hexagonal wurtzite structure, which belongs to the space group $\mathrm{C}_{6 \mathrm{v}}^{4}$. It is generally agreed that stress arises from the mismatch of thermal expansion coefficients of the films and the substrates, or the lattice mismatch and distortion. Doping is considered to be the main factor that causes the lattice distortion of the crystals, for it is usually different from the atomic radii of different elements (Huang et al., 2003). Figure 3 shows the Raman band of the undoped $\mathrm{ZnO}$ and doped with $\mathrm{Sn}$ at 5, 10 and 15\%. Most positions of the modes are shifted. This indicates that the addition of $\mathrm{Sn}$ strengthens the tensile stress of the $\mathrm{ZnO}$ crystals. Theoretically, it is difficult to substitute $\mathrm{Zn}^{2+}$ with $\mathrm{Sn}^{4+}$ 
Am. J. Engg. \& Applied Sci., 3 (1): 171-179, 2010

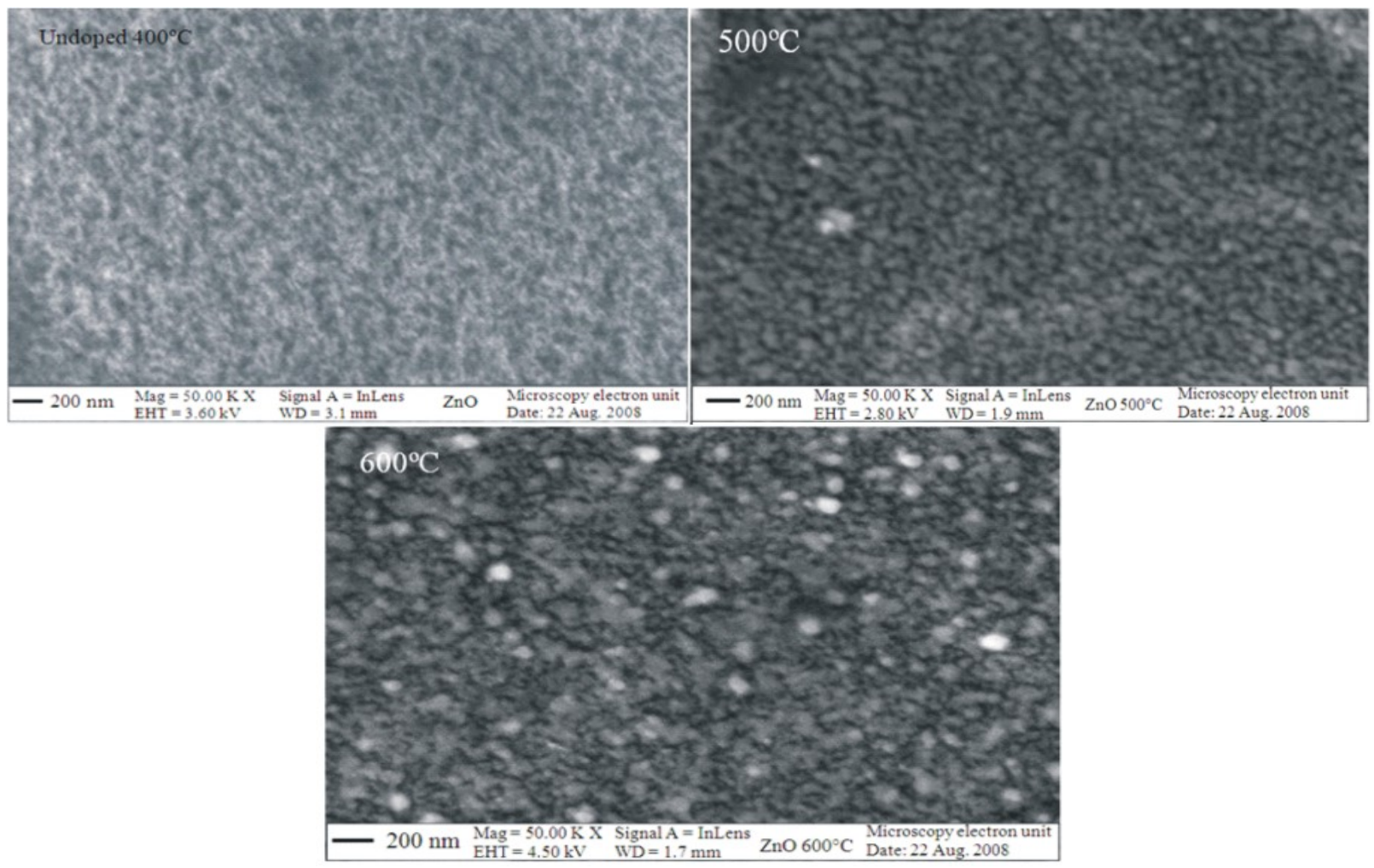

(a)
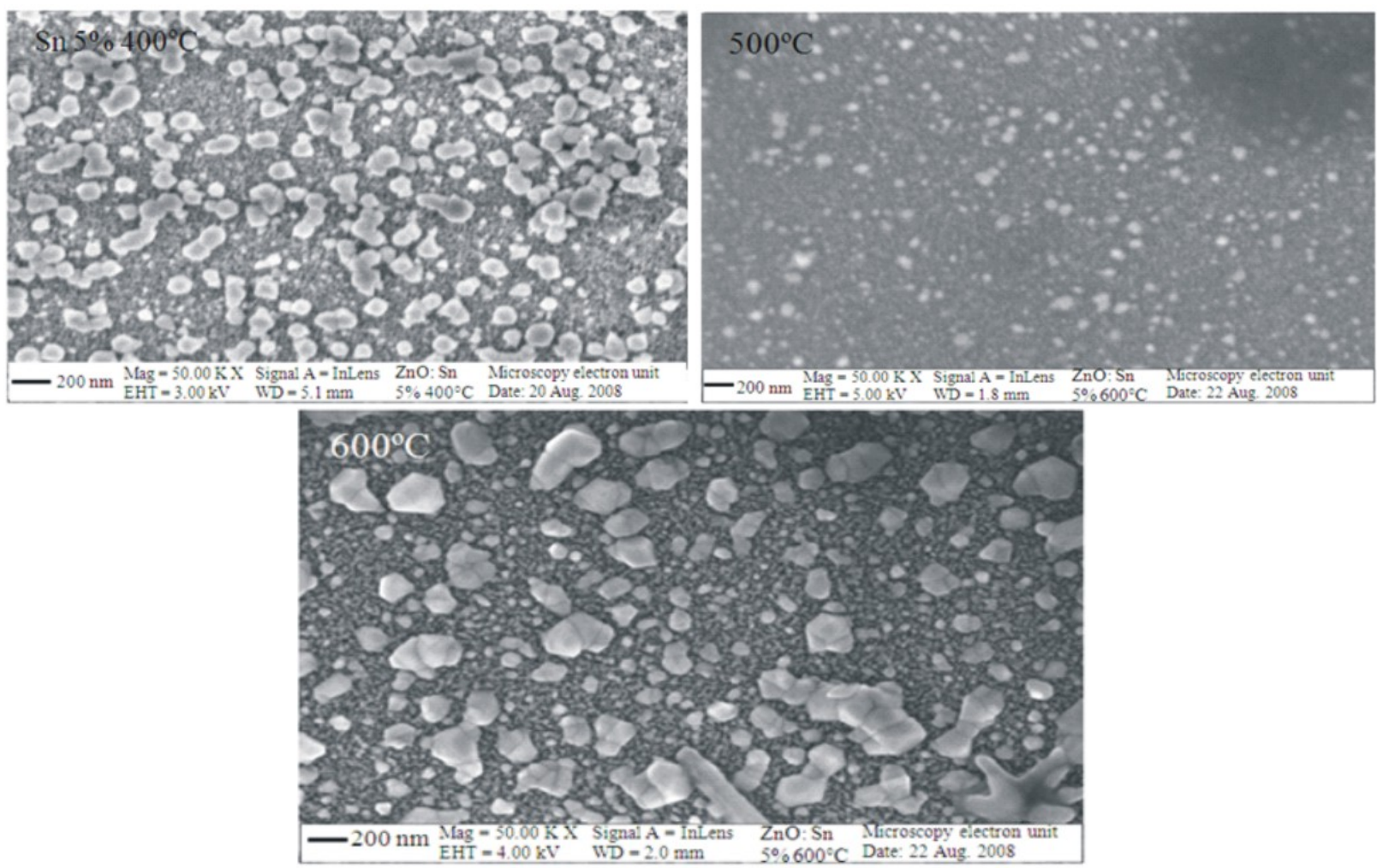

(b) 
Am. J. Engg. \& Applied Sci., 3 (1): 171-179, 2010
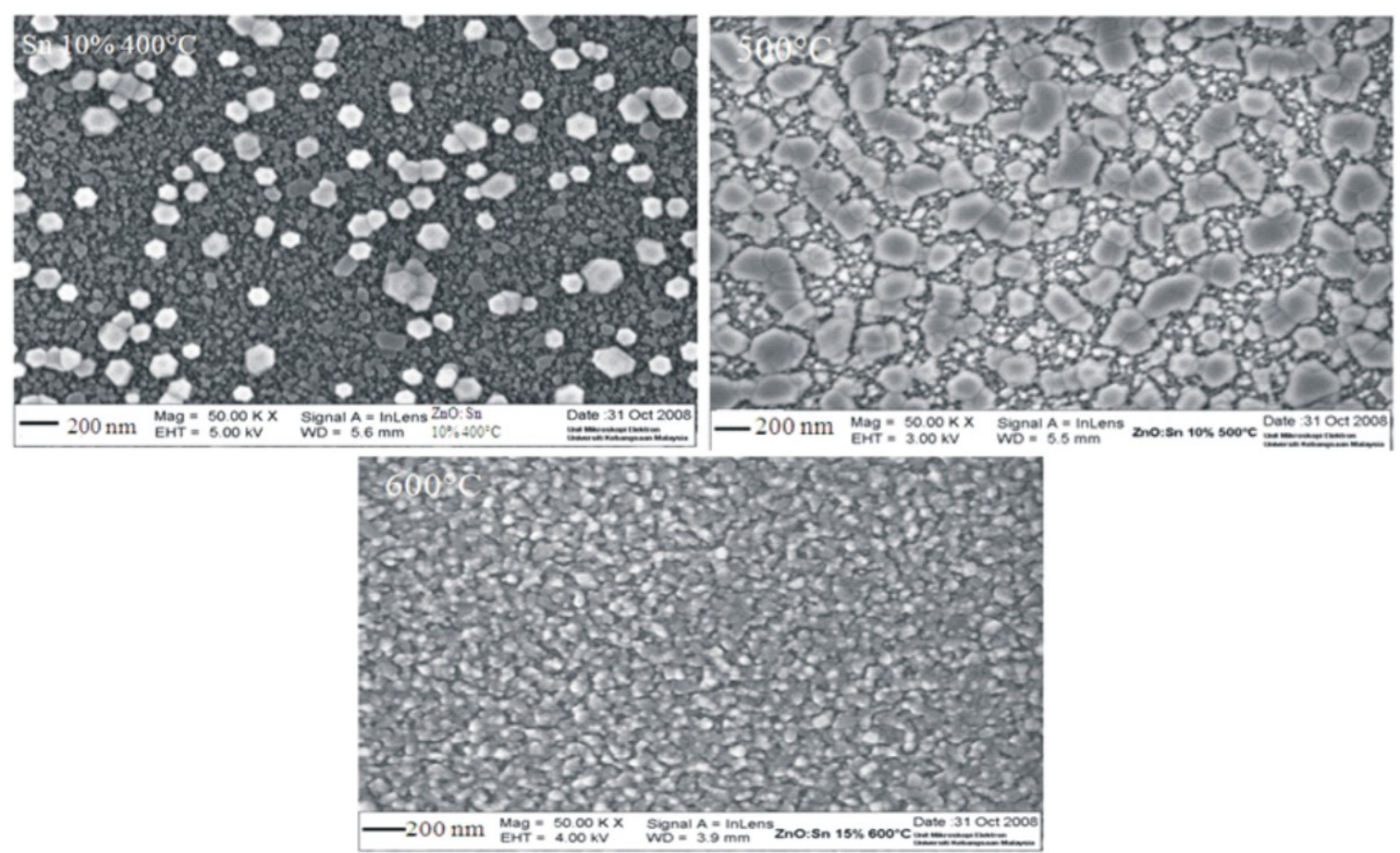

(c)
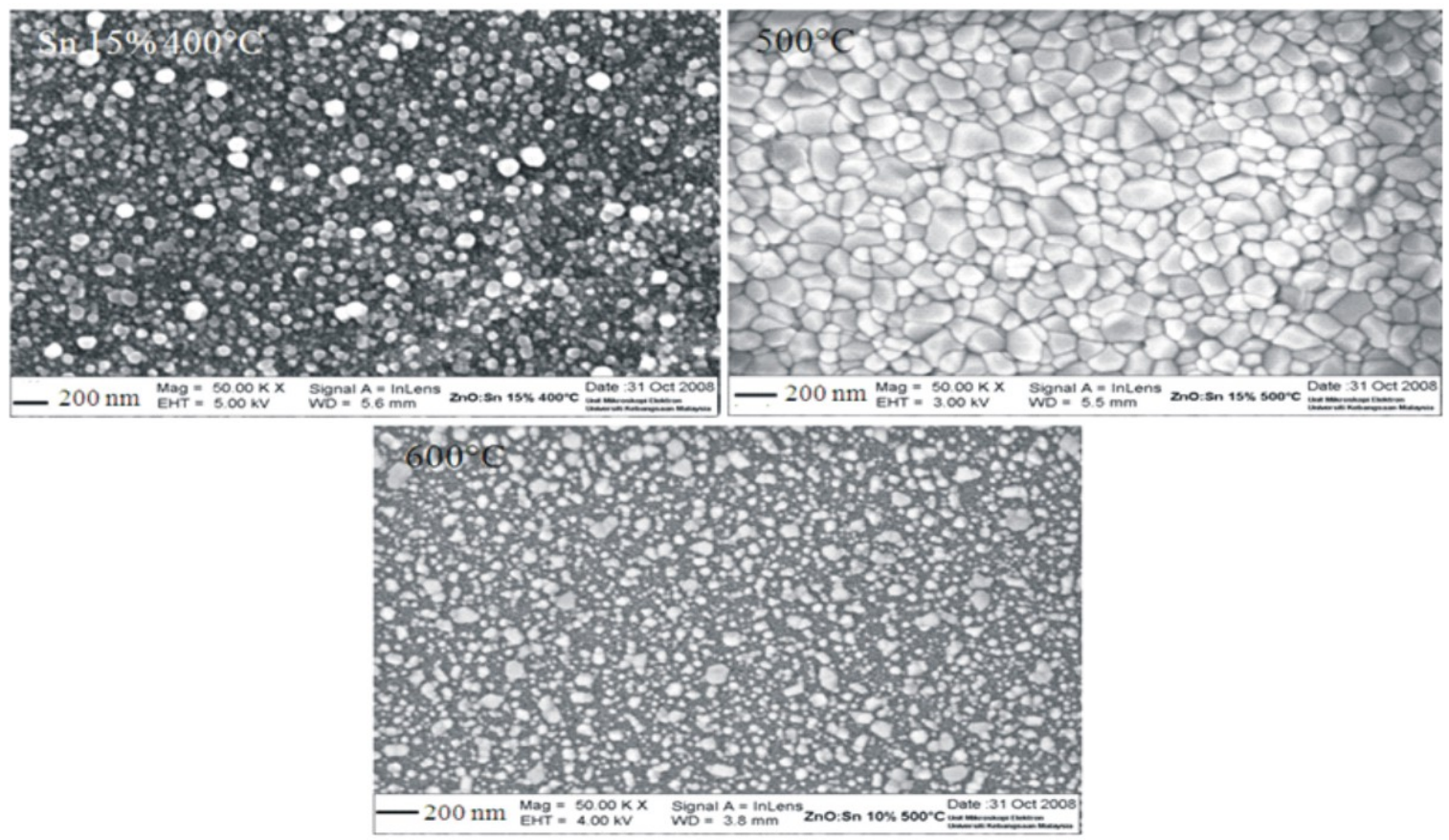

(d)

Fig. 2: SEM images of undoped and doped $\mathrm{ZnO}$ thin films with Sn dopant content, (a) undoped; (b) $\mathrm{x}=0.05$; (c) $\mathrm{x}=0.10$ and $(\mathrm{d}) \mathrm{x}=0.15$

in $\mathrm{ZnO}$ crystal, for the radius of $\mathrm{Sn}^{4+}$ is much larger than that of $\mathrm{Zn}^{2+}$. The liquid phase penetrates into the boundaries between $\mathrm{ZnO}$ grains and enhances the grain growth and the densification of the film. This process 


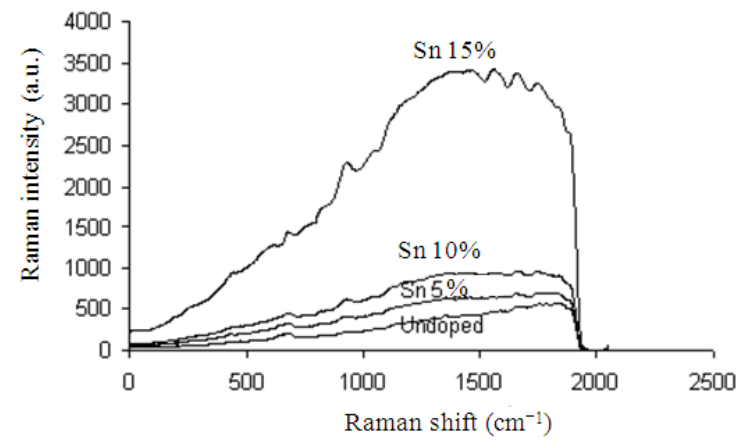

Fig. 3: Raman spectroscopy of undoped and doped $\mathrm{ZnO}$ with $\mathrm{Sn}$ at 5,10 and $15 \%$ before annealing and in liquid form

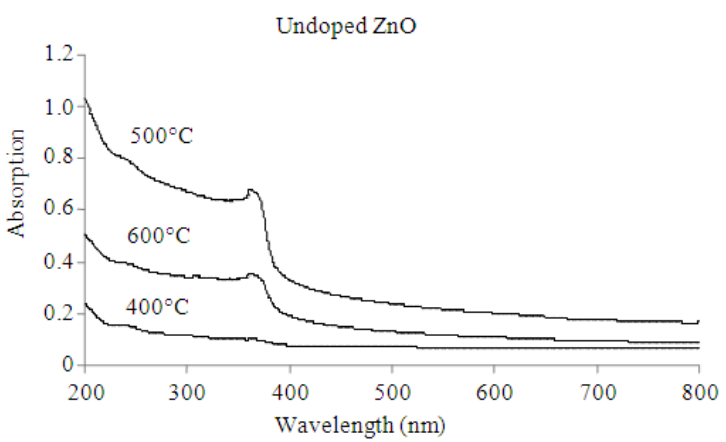

(a)

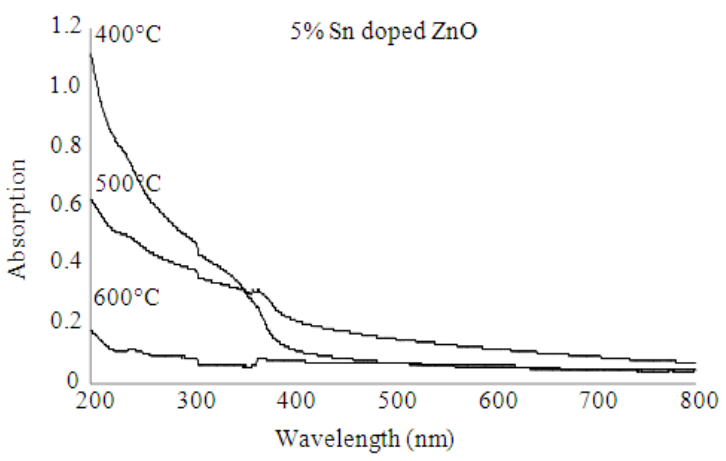

(b)

Fig. 4: Optical absorption spectra of undoped and doped $\mathrm{ZnO}$ with $\mathrm{Sn}$ at $5 \%$ thin films

can strengthen the interfacial stress of the $\mathrm{ZnO}$ grains, which may be the main cause of the shift of the modes in the Raman spectrum. Nevertheless, if there are any effects to the microstructure of $\mathrm{ZnO}$ crystal by $\mathrm{Sn}^{4+}$, the possibility could not be excluded, for solid solubility of $\mathrm{Sn}$ in $\mathrm{ZnO}$ at 5, 10 and $15 \%$.

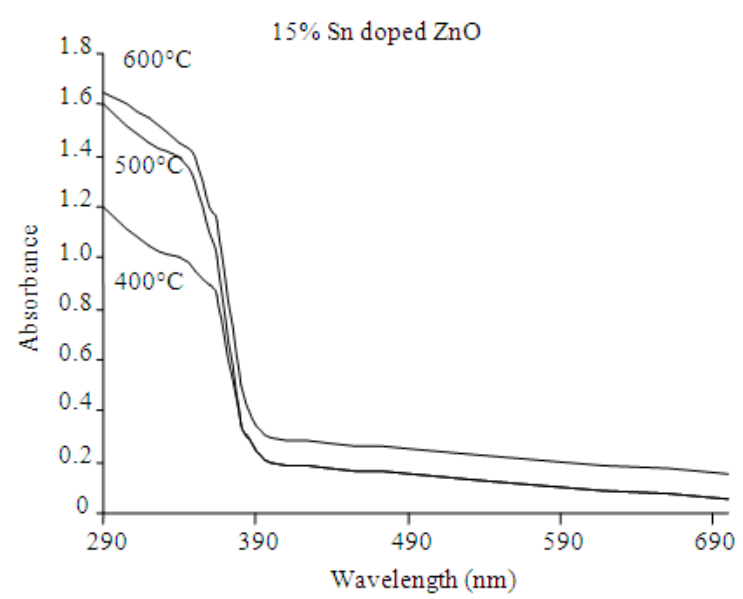

(a)

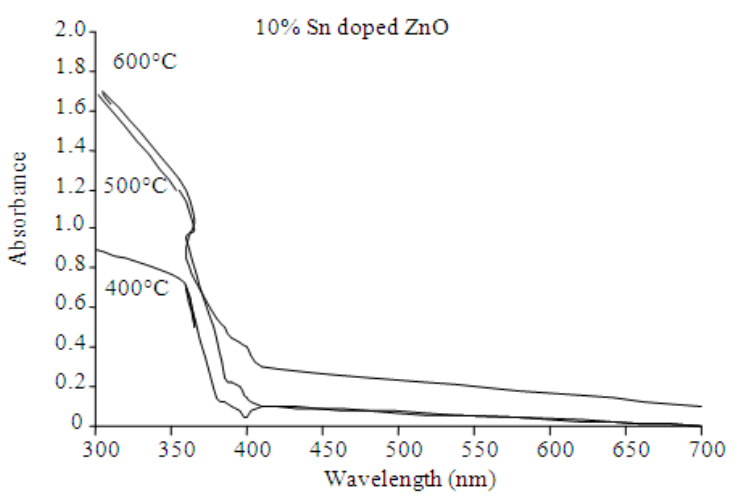

(b)

Fig. 5: Optical absorption spectra of doped $\mathrm{ZnO}$ with Sn at 10 and $15 \%$ thin films

In the Raman spectra of Sn-doped $\mathrm{ZnO}$ films, there are additional modes that can be observed. Thus, we can relate it to the intrinsic host defects, for instance, oxygen vacancies. A higher intensity of the vibration mode indicating a higher concentration of oxygen vacancies might be in $\mathrm{Zn}-\mathrm{Sn}-\mathrm{O}$ films than that of $\mathrm{ZnO}$ films. As a donor, more oxygen vacancies lead to higher conductive band electron density, which will enhance the sp-d interactions and lead to a red-shift of the band gap.

The absorption spectra with wavelengths from 200$800 \mathrm{~nm}$ of the undoped and doped $\mathrm{ZnO}$ thin films are presented in Fig. 4 and 5. The absorption edges were defined as the wavelengths at intersections that were obtained by extrapolating the horizontal line and the sharply rising portions of the UV-Vis absorption curves as can be seen in Fig. 4 and 5 also have been reported by Wong and $\mathrm{Xu}$ (2004). The absorption of undoped $\mathrm{ZnO}$ 
films at $500^{\circ} \mathrm{C}$, at $5 \% \mathrm{Sn}$ at $400^{\circ} \mathrm{C}$ and $600^{\circ} \mathrm{C}$ for 10 and $15 \% \mathrm{Sn}$ were higher than those of the others for each temperature. In the case of undoped $\mathrm{ZnO}$ films, the absorption at annealing temperature of $500^{\circ} \mathrm{C}$ was higher, but the absorption at temperatures 400 and $600^{\circ} \mathrm{C}$ were lower than $500^{\circ} \mathrm{C}$. In particular, the absorption of tin doped films decreases with decreasing annealing temperature. As seen from the SEM images in Fig. 2, the lower absorption in tin doped films may be due to the increase in optical scattering caused by the mixing of small and large particles as well as its rough surface and morphology.

The optical band-gap, $E_{g}$, is determined from the absorption spectra using equation (Tauc et al., 1966):

$(\alpha h v)^{2}=\mathrm{C}\left(\mathrm{hv}-\mathrm{E}_{\mathrm{g}}\right)$
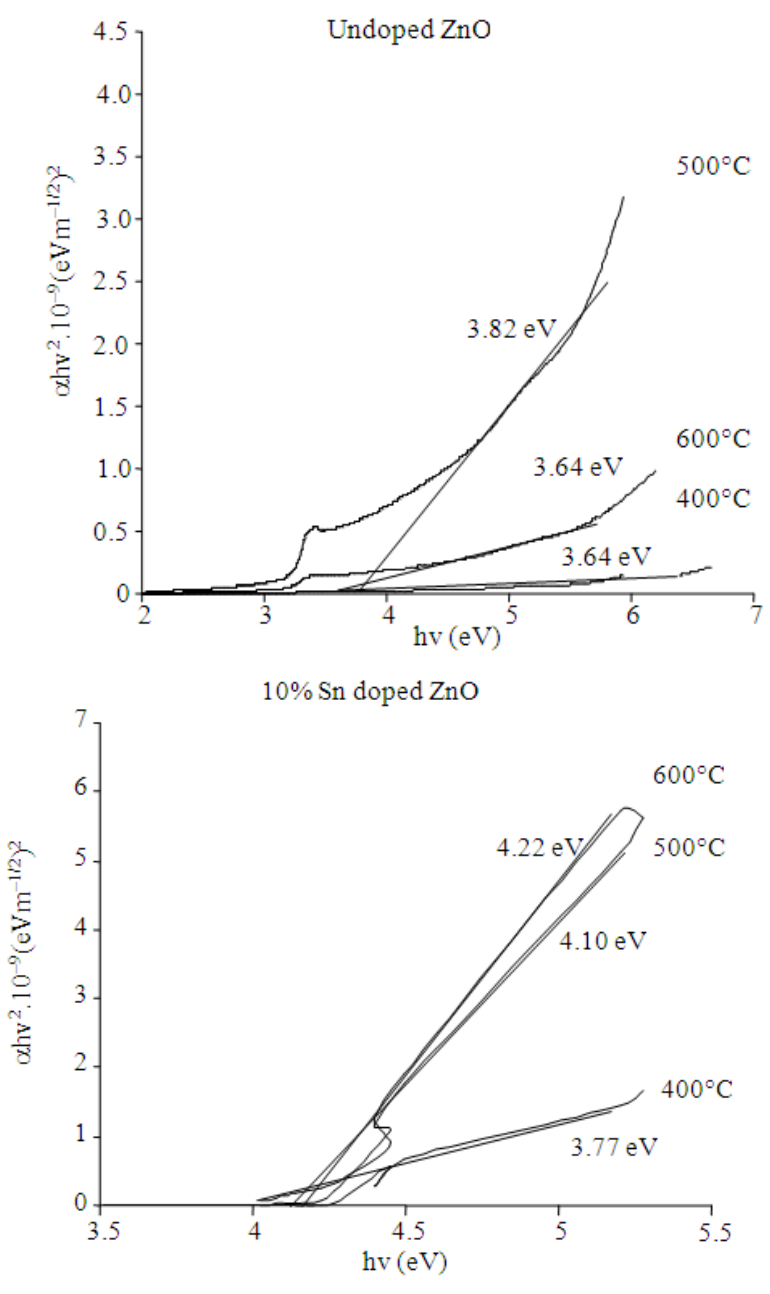

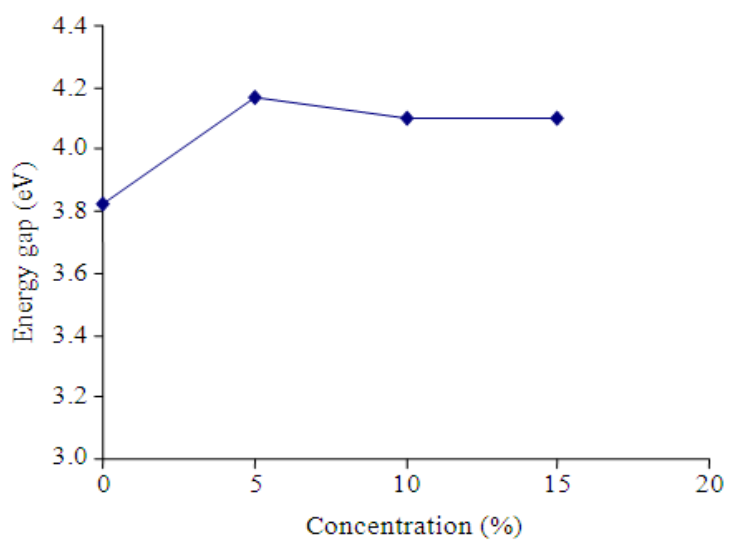

Fig. 6: Graph of different Sn concentration (\%) Vs energy gap at $500^{\circ} \mathrm{C}$
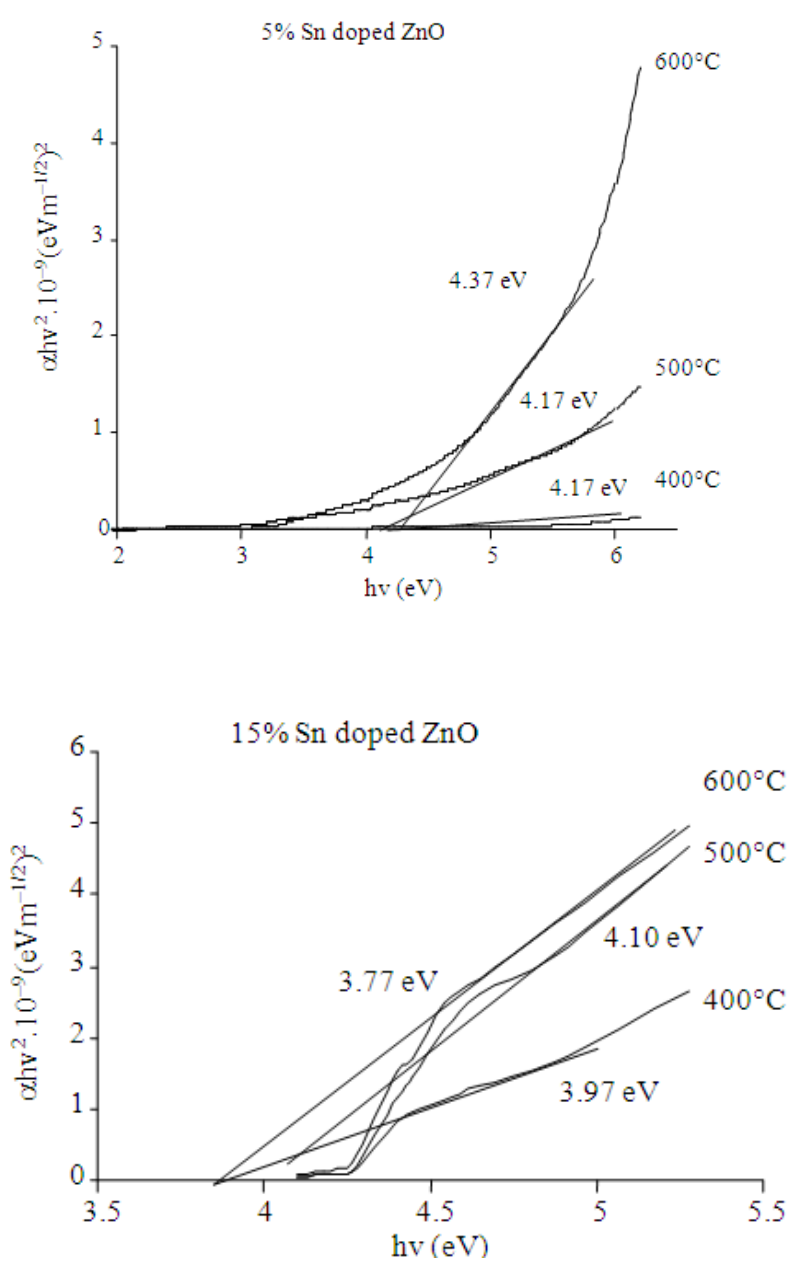

Fig. 7: Evoluation of $(\alpha \mathrm{hv})^{2}$ Vs hv curves of films prepared, at different annealed temperature 
related to direct transitions in $\mathrm{ZnO}$ crystals, with constant $\mathrm{C}$ depending on the electron-hole mobility.

Figure 6 shows that the energy gap increases with the increase of $\mathrm{Sn}$ concentration at $500^{\circ} \mathrm{C}$. The $(\alpha \mathrm{hv})^{2}$ Vs hv plots are shown in Fig. 7. Independent of the preparation method (undoped or doped with $\mathrm{Sn}$ ) the determined optical band-gap of the samples varies depending on the annealing temperature i.e. between 3.64 and $4.37 \mathrm{eV}$. The largest values of $\mathrm{E}_{\mathrm{g}}$ is determined for textured films (( $\left(\begin{array}{lll}0 & 0 & 2\end{array}\right)$ orientation $)$ prepared from films with $500^{\circ} \mathrm{C}$ annealed temperature (Fig. 1). The value of $4.37 \mathrm{eV}$ is notably larger than that of the optical band-gap reported for monocrystalline $\mathrm{ZnO}$. In general, blue shift of the absorption onset of $\mathrm{Sn}$ doped nanocrystalline films is associated with the increase of the carrier concentration blocking the lowest states in the conduction band, well known as the Burstein-Moss effect (Burstein, 1954). In order to describe the experimentally found blue shift in Sn doped films, the displacement polarization effects and structural disorder is considered as additional factors that affect the shape of the band tails. This theory of band-gap widening for polar semiconductors is proposed by Valle at al. (2004). Although the band-gap widening in most of the studied films can be justified by this model, the band-gap values of more than $4.3 \mathrm{eV}$ found in textured samples containing relatively small crystallites are not well understood. It is suggested that the quantum confinement phenomena induced by the nanoscopic size of the crystallites also contribute to this effect.

As a result, as the film is oriented more preferentially along $\left(\begin{array}{lll}0 & 0 & 2\end{array}\right)$ direction, the grain size of the film increased, the $\mathrm{Zn}$ content decreased, the tensile stress of the $\mathrm{ZnO}$ crystals increased and the absorption increased as well.

\section{CONCLUSION}

The results of tin doped $\mathrm{ZnO}$ thin films prepared by the sol-gel method show that the nanostructure of films annealed at intermediate temperature $\left(500^{\circ} \mathrm{C}\right)$ is clearly different than those prepared at lower or higher temperature. All films were oriented preferentially along the $\left(\begin{array}{lll}0 & 0 & 2\end{array}\right)$ direction. The XRD patterns of the samples are polycrystalline and exhibit single phase hexagonal structure. Films doped with at 5\% tin concentration at $500^{\circ} \mathrm{C}$ had stronger c-axis orientation perpendicular to the substrate and smaller grain than the others. The surface morphology of the films showed that the films strongly depend on the annealing temperature. In Raman spectra, the modes shift to lower wavenumbers and to higher wavenumbers, respectively.
When the films were doped with Sn, it is discovered that the tensile residual stress and the free carrier concentration increase with doping. The optical bandgap of about $4.3 \mathrm{eV}$ is considerable larger than that of nanocrystalline $\mathrm{ZnO}$ and cannot be described by the standard theories for band-gap widening.

\section{ACKNOWLEDGEMENT}

The researchers would like to thank Photonic Technology Laboratory, Institute of Microengineering and Nanoelectronics, University Kebangsaan Malaysia. This study was partially supported by a grant from Ministry of Higher Education (UKM-RS-06FRGS0001-2007).

\section{REFERENCES}

Burstein, E., 1954. Anomalous optical absorption limit in InSb. Phys. Rev., 93: 632-633.

Huang, Y., M. Liu, Z. Li, Y. Zeng and S. Liu, 2003. Raman spectroscopy study of ZnO-based ceramic films fabricated by novel sol-gel process. Mater. Sci. Eng., B97: 111-116.

Kashiwaba, Y., F . Katahira, K. Haga, T. Sekiguchi, H. Watanabe, 2000. Hetero-epitaxial growth of $\mathrm{ZnO}$ thin films by atmospheric pressure CVD method. J. Cryst. Growth, 122: 431-434.

Lee, J.H. and B.O. Park, 2003. Transparent Conducting $\mathrm{ZnO}$ : Al. In and Sn thin films deposited by the solgel method. Thin Solid Films, 426: 94-99.

Look, D.C., 2001. Recent advances in $\mathrm{ZnO}$ materials and devices. Mater. Sci. Eng., B80: 383-387.

Nunes, P., D. Costa, E. Fortunato and R. Martins, 2002. Performances presented by zinc oxide films deposited by RF magnetron sputtering. Vacuum, 64: 293-297.

Nunes, P., E. Fortunato, P. Tonello, F. Branz Fernandes, P. Vilarinho and R. Martins, 2002. Effect of different dopant elements on the properties of $\mathrm{ZnO}$ thin films. Vacuum, 64: 281-285.

Paraguay, F.D., W.L. Estrada, D.R.N. Acosta, E. Andrade and M. Miki Yoshida, 1999. Growth, structure and optical characterization of high quality $\mathrm{ZnO}$ thin films obtained by spray pyrolysis. Thin Solid Films, 350: 192-202.

Shan, F.K., B.C. Shin, S.C. Kim and Y.S. Yu, 2003. Substrate effect of $\mathrm{ZnO}$ thin films prepared by PLD. J. Eur. Cerm. Soc., 24: 1015-1018.

Shan, F.K., B.C. Shin, S.C. Kim and Y.S. Yu, 2004. Optical properties of as doped $\mathrm{ZnO}$ thin films prepared by PLD technique. J. Eur. Cerm. Soc., 24: 1861-1864. 
Shim, E.S., H.S. Kang, J.S. Kang, J.H. Kim and S.Y. Lee, 2002. Effect of the variation of film thickness on the structural and optical properties of $\mathrm{ZnO}$ thin films deposited on sapphire substrate using PLD. Applied Surf. Sci., 186: 474-476.

Tauc, J., R. Gricorovichi and A. Vancu, 1966. Optical properties and electronic structure of amorphous germanium. Phys. Status Solidi, 15: 627-633.
Valle, G.G., P. Hammer, S.H. Pulcinelli and C.V. Santilli, 2004. Transparent and conductive $\mathrm{ZnO}$ : $\mathrm{Al}$ thin films prepared by sol-gel dip-coating. J. Eur. Cerm. Soc., 24: 1009-1013.

Wong, C. and B.Q. Xu, 2004. Synthesis and optical absorption property of the $\mathrm{Zn}_{2} \mathrm{Ti}_{x} \mathrm{Sn}_{1-x} \mathrm{O}_{4}(0 \leq \mathrm{x} \leq 1)$ solid solutions. Sol. St. Phen., 177: 3448-3453. 